\title{
Colloidal and rheological behavior of aqueous dispersions of buriti tree (Mauritia flexuosa) gum
}

\author{
Diego Aires da Silva ${ }^{1,2}$, Pedro Henrique Santos ${ }^{3}$, Rosinelson da Silva Pena ${ }^{1 *}$ \\ ${ }^{1}$ Graduate Program in Food Science and Technology, Technology Institute, Federal University of Pará (UFPA), Postal code: 66075-110, Belém, \\ PA, Brazil, ${ }^{2}$ Food Technology Department, Natural Science and Technology Center, University of Pará State (UEPA), Postal code: 66050-540, \\ Belém, PA, Brazil, ${ }^{3}$ Chemical and Food Engineering Department, Santa Catarina Federal University (UFSC), Campus Trindade, Florianópolis, \\ SC, Brazil
}

\section{A B S TRACT}

\begin{abstract}
The temperature, concentration and $\mathrm{pH}$ variables influence the aqueous dispersion of the gum properties. In this context, the aims of this research were to characterize the gum obtained from the buriti tree (Mauritia Flexuosa) trunk exudate, as well as to evaluate the colloidal and rheological behavior of the aqueous dispersions of this gum. Thus, the centesimal composition, absolute zeta $(\zeta)$ potential as a function of $\mathrm{pH}(1.2$ to 4.0$)$, particle size distribution, as well as the rheological properties of the gum at different temperatures $(15,20,25,30$, and $\left.40{ }^{\circ} \mathrm{C}\right)$ and concentrations $(4,5,8$, and $10 \%(\mathrm{~m} / \mathrm{v}))$ were studied. In addition, the Newton, Power Law, and Herschel-Bulkley models were fitted to the rheological data. Buriti tree gum (BG) was found to have $10.43 \%$ moisture, $5.05 \%$ ashes, $0.68 \%$ lipids, $3.09 \%$ proteins, and $80.76 \%$ carbohydrate. The aqueous dispersion of the gum (1\%) had a $\zeta$ value of $-17.1 \mathrm{mV}$ with a tendency for greater stability at $\mathrm{pH}<4$ and polydisperse particle size distribution ( $45 \mathrm{~nm}$ to $648.1 \mathrm{~nm}$ diameter) with PDI (polydispersity index) of 1 . The aqueous dispersion with 4 and $5 \%$ gum had typical Newtonian fluid behavior and became pseudoplastic at concentrations of 8 and $10 \%$. The Herschel-Bulkley model had the best fit to the rheological data $\left(r^{2}>0.99\right)$. Gum dispersion viscosity decreased with higher temperature and lower concentration. The activation energy $\left(E_{a}\right)$ value for gum dispersion ranged from 9.07 to $17.35 \mathrm{~kJ} / \mathrm{mol}$.
\end{abstract}

Keywords: Buriti tree gum; Colloidal properties; Mauritia flexuosa; Rheology; Viscosity

\section{INTRODUCTION}

Gums are carbohydrates with high molecular weight that are water soluble and insoluble in most organic solvents (Imam et al., 2013). They may be obtained from various sources, such as seeds (guar gum), algae (carrageenan gum), microorganisms (xanthan gum), and plant exudates (gum arabic), which have different properties and applications depending on their origin and chemical composition (Nussinovitch, 2010). That has been driving the investigation of new gum sources, among which the gum obtained from the exudate produced in the trunk of buriti tree (Mauritia flexuosa). The buriti tree is a palm of the family Arecaceae that is very abundant in the North region of Brazil. Its fruits are used as food and the leaves and stalks are used to make utensils and handicraft (Smith, 2014).

Knowing the rheological and colloidal parameters of gums is a valuable tool to characterize both their flow and deformation and their behaviors dependent on the solids content or changes in particle size and surface charges of the particles governing the stability of the polysaccharides in solution (Phillips, 2000). Such knowledge is key for processes to modify the texture and for determining the emulsifying stability or phase separation when the gums are added to formulations, such as in foods or drugs (Yaseen et al., 2005).

The stabilizing, emulsifying, and gelling role of gums prevent undesirable changes in foods such as crystallization of sugars and sedimentation, as well as other physical transformations that must be controlled to achieve good product acceptance (Paraskevopoulou et al., 2005).

Several factors may impact the rheological behavior of fluid foods, such as temperature, concentration, and particle size (Tonon et al., 2009). Significant changes in the rheological properties of polysaccharide fluids may occur due to

\footnotetext{
${ }^{*}$ Corresponding author:

Dr. Rosinelson da Silva Pena. Faculdade de Engenharia de Alimentos, Universidade Federal do Pará (UFPA) - Rua Augusto Corrêa, 01,

P.O. Box 479, Postal code: 66075-110, Belém, PA, Brazil. Phone: +55-91-3201-8994. Fax: +55-91-3201-8861. E-mail: rspena@ufpa.br
}

Received: 31 August 2017; Revised: 08 October 2017; Accepted: 09 October 2017; Published Online: 19 October 2017 
temperature, concentration, pressure, or shear rate. All those factors directly influence the inter- and intramolecular interactions of polymers, reorienting them or impacting hydrogen bonds and Van der Waals interactions, which changes their properties (Eddy et al., 2014).

Since different temperatures are usually used during processing of hydrocolloids, their rheological properties must be studied as a function of this variable. Moreover, the apparent viscosity of hydrocolloids as function of concentration is generally described by either an exponential or a power relationship (Rao, 1999). The Arrhenius mathematical model is used to determine the influence of temperature on the rheological behavior of a product, relating apparent viscosity values to temperature (Rao, 2013). Likewise, the influence of solids concentration on viscosity may be estimated by an exponential model or by a power model (Rao, 1999).

The mathematical modeling of the experimental data is an important key on the knowledge of the product's rheological behavior since rheological model factors provide essential information on defining unit operations such as pumping, mixture systems, thermal treatment and concentration (Rao, 1999; Silva et al., 2005).

Based on that, this study aimed to investigate the effect of temperature and concentration on the rheological behavior of the gum obtained from the exudate produced in buriti tree trunk, as well as to perform the mathematical modeling of the effect of those variables on product viscosity. Furthermore, the influence of the gum's particle surface charges when the gum is found in aqueous dispersions was assessed.

\section{MATERIAL AND METHODS}

\section{Obtaining and purifying buriti tree gum}

The raw buriti tree exudate was collected in April 2015 in the Cametá Tapera Island (Pará, Brazil) (2 ${ }^{\circ} 09^{\prime} 02.77^{\prime} \mathrm{S}$ and $49^{\circ} 26$ '15.57" W) directly from the trunk at $0.8 \mathrm{~m}$ from the soil and stored in polyethylene bags at $25{ }^{\circ} \mathrm{C}$ for up to 24 hours. In order to obtain the gum, the raw exudate was suspended in distilled water $(1: 10, \mathrm{w} / \mathrm{v})$ at room temperature $\left(\approx 25^{\circ} \mathrm{C}\right)$ for $24 \mathrm{~h}$ with no stirring. Next, the dispersion was filtered in $1 \mathrm{~mm}$ mesh and the filtrate was centrifuged at 2,778 $\mathrm{x} g$ for $10 \mathrm{~min}$ (Suprafug 22, Heraeus Sepatech, CA, USA). The impurities retained were discarded and the supernatant was added with ethanol p.a. (1:3, gum solution:ethanol, v/v). The buriti tree gum (BG), composed of the precipitated fraction, was dried in a forced air oven $\left(50^{\circ} \mathrm{C} / 24 \mathrm{~h}\right)$, ground, and stored in amber flasks at $25^{\circ} \mathrm{C}$.

\section{Gum centesimal composition}

The contents of moisture, ashes, lipids, and proteins (nitrogen-protein conversion factor of 6.25) of BG were determined according to the methodologies recommended by the Association of Official Analytical Chemists (AOAC, 1995). Total carbohydrates were estimated by difference $(100-(\%$ moisture + ashes + lipids + proteins $))$.

\section{$\zeta$ potential}

The $\zeta$ potential was measured in a ZetaSizer Nano Zs (Malvern Instrument, Worcestershire, UK) device in capillary cells (model DTS 1060) bundled in the basic package of the ZetaSizer device and connected to a Malvern Instrument MPT-2 automated multi purpose titrator. BG suspensions in water were prepared and maintained under mechanical stirring for $15 \mathrm{~min}$ in an Ultra Turrax disperser at $3,780 \times \mathrm{g}$ for $1 \mathrm{~h}$. Next, the $\mathrm{pH}$ of the BG suspensions was gradually adjusted with nitric acid (0.1 M) and sodium hydroxide $(0.1 \mathrm{M})$ solutions.

\section{Particle size distribution}

A Malvern ZetaSizer reading at $633 \mathrm{~nm}$ radiation device was used to determine particle size distribution at $25^{\circ} \mathrm{C}$. Deionized water was used as blank (Mirhosseini et al., 2008). The polydispersity index was calculated based on the correlation between the dispersion measured and the dispersion predicted by the light dispersion theory (Maranzano and Wagner, 2001).

\section{Rheological characterization}

The rheological tests to assess flow were carried out using a Brookfield R/S Plus (Brookfield Engineering Labs, Middleboro-MA, USA) rheometer in cone and plate geometry operating in CR (controlled rate) mode with controlled shear rates $(\gamma)$ and shear stress $(\tau)$ values obtained in a pre-defined time interval. The analyses were performed in $\mathrm{BG}$ dispersions with different concentrations $(4,5,8$, and $10 \% \mathrm{~m} / \mathrm{v})$ and, for each dispersion, the runs were carried out at different temperatures $(15,20,25,30$, and $40^{\circ} \mathrm{C}$ ). The concentrations and temperatures employed were chosen based on previous studies on gum dispersion (Fadavi et al., 2014; Eren et al., 2015).

The system temperature was maintained by a temperaturecontrolled water bath (Lauda 3200, Köningshofen, Germany) coupled to the rheometer. The total analysis time was $120 \mathrm{~s}$, at $60 \mathrm{~s}$ for ramp up and $60 \mathrm{~s}$ for ramp down. Due to the lack of thixotropy effect, the mean value between the two ramps was used for mathematical modeling. The pre-defined shear rate ranged from 0 to $600 \mathrm{~s}^{-1}$ with points obtained every $2 \mathrm{~s}$ (variation of $20.68 \mathrm{~s}^{-1}$ in the shear rate at every point) for a total of 30 points for each curve. All analyses were carried out in triplicate. 


\section{Rheological modeling}

Several mathematical models are used in rheological studies in order to understand the effects of applying the shear rates in polymeric dispersions at the molecular level. This study used the Newton (Eq. 1), Power Law (Eq. 2), and Herschel-Bulkley (Eq. 3) models (Rao, 2013).

$$
\begin{aligned}
\tau & =\mu \gamma \\
\tau & =\kappa \gamma^{\mathrm{n}} \\
\tau & =\tau_{0}+\kappa_{\mathrm{h} \beta} \gamma^{\mathrm{n}_{\mathrm{h} \beta}}
\end{aligned}
$$

Where, $\tau=$ shear stress $(\mathrm{Pa}) ; \mu=$ viscosity $(\mathrm{Pa} . \mathrm{s}) ; \gamma=$ shear rate $\left(\mathrm{s}^{-1}\right) ; \tau_{0}=$ yield stress $(\mathrm{Pa}) ; n, n_{\mathrm{h} \beta}=$ flow behavior indices (dimensionless); $k$, $k_{\mathrm{h} \beta}=$ consistency indices $\left(\mathrm{Pa} \cdot \mathrm{s}^{\mathrm{n}}\right)$.

\section{Influence of temperature on rheological behavior}

The Arrhenius equation (Eq. 4) was used to assess the influence of temperature on the product's apparent viscosity $\left(\mu_{a p}\right)$, whose values were determined by the ratio of the shear stress by a shear rate of $310 \mathrm{~s}^{-1}$ (Alghooneh et al., 2017). According to Steffe (1996), the typical shear rate for industrial processes of mixing and pumping foods may range from $1 \mathrm{~s}^{-1}$ up to $1,000 \mathrm{~s}^{-1}$.

$\mu_{\text {ap }}=\mathrm{A}_{0}+\left(\frac{\mathrm{Ea}}{\mathrm{RT}}\right)$

Where, $\mu_{a p}=$ apparent viscosity (Pa.s); $A_{0}=$ empirical constant (Pa.s); $E_{a}=$ activation energy $(\mathrm{kJ} / \mathrm{mol}) ; \mathrm{R}=$ gas constant $(0.008314 \mathrm{~kJ} / \mathrm{mol} . \mathrm{K}) ; \mathrm{T}=$ temperature $(\mathrm{K})$.

\section{Statistical analysis}

Non-linear regression in the software Origin 8.0 (OriginLab, Middleboro-MA, USA) was used to fit the mathematical models to the experimental data. The coefficient of determination $\left(r^{2}\right)$ and reduced chi-squared $\left(\chi^{2}\right)$ values were used to assess the quality of the mathematical fits.

\section{RESULTS AND DISCUSSION}

\section{BG centesimal composition}

The analyses found $10.43 \%( \pm 0.13)$ moisture, $5.05 \%$ $( \pm 0.08)$ ashes, $0.68 \%( \pm 0.09)$ lipids, $3.09 \%( \pm 0.19)$ proteins, and $80.76 \%( \pm 0.92)$ carbohydrate in the BG. This composition is very similar to that observed for gum from Acacia farnesiana, which had $12.02 \%$ moisture, $4.48 \%$ ashes, $0.85 \%$ lipids, $3.59 \%$ proteins, and $79.06 \%$ carbohydrates (Sibaja-Hernández et al., 2015). In addition, Bashir and Haripriya (2016) observed the following composition for gum arabic: $10.77 \%$ moisture, $2.90 \%$ ashes, $0.37 \%$ lipids, $1.75 \%$ proteins, and $84.21 \%$ carbohydrates. From the technological standpoint, the similarity of the $\mathrm{BG}$ composition with that of gum arabic may be an important indication of the product's industrial application.

Sibaja-Hernández et al. (2015) highlight the importance of the interaction between proteins and the polysaccharide, such as interface anchoring groups of gums in oil droplets or other hydrophobic substances, which is directly related to the viscoelastic and stability properties of the emulsion. In that context, Al-Assaf et al. (2009) observed that the protein-arabinogalactan fraction of a proteinpolysaccharide complex was responsible for the emulsifying activity of gum arabic.

\section{BG $\zeta$ potential}

The $\zeta$ potential of the BG aqueous dispersion was $-17.1 \mathrm{mV}$ $( \pm 2.69)$. Vasile et al. (2016) observed $\zeta$ potential values of -43.50 and $-45.85 \mathrm{mV}$ for the gum obtained from exudate of Prosopis alba and -41.20 and $-36.10 \mathrm{mV}$ for gum arabic in dispersions with 2 and $5 \%$ gum, respectively. The negative character of the dispersion's $\zeta$ potential may be attributed to the neutral nature of BG. According to Carneiro-da-Cunha et al. (2011), the stability of aqueous systems is better for $\zeta$ potential values between $-30 \mathrm{mV}$ and $+30 \mathrm{mV}$, conditions in which the surface charges repeal each other. In turn, colloidal instability increases as the $\zeta$ potential value gets closer to $0 \mathrm{mV}$.

According to Bohmer et al. (1990), the stability of polymeric dispersions in emulsions depends on steric stability, which results from the interaction between the polymer and the particle surface, for example. As all particles already covered by the polymer get closer, osmotic pressure increases (caused by the spatial confinement of the complex formed between the polymer and the particles), which may induce a repulsive force. Moreover, according to those same authors, there is also dependence with the double-layer particle-particle electrostatic stability, which is effective at distances comparable to the Van der Waals attraction forces. However, the particle-particle electrostatic system depends on good colloidal stability of polysaccharides so they are able to perform their emulsifier role well (SibajaHernández et al., 2015).

The variation in $\zeta$ potential as a function of $\mathrm{pH}$ of the BG aqueous dispersion can be seen in Fig. 1. According to that figure, when $\mathrm{pH}$ gets close to 1 , the $\zeta$ potential reaches values close to $0 \mathrm{mV}$, which may cause instability in the gum's dispersion (Abdolmaleki et al., 2016). In turn, at $\mathrm{pH}>2$, the dispersion's $\zeta$ potential drastically drops and reaches a value of approximately $-20 \mathrm{mV}$ at $\mathrm{pH} 4$. The curve's trend suggests that the dispersion of BG will reach a $\zeta$ potential value of $-30 \mathrm{mV}$ at $\mathrm{pH}$ between 4 and 5 . Thus, based on the DLVO theory, which admits that only the Van der Waals and electric forces determine the degree 
of stability of colloids (Cruz et al., 2017), this is the pH range of greatest colloidal stability of the $\mathrm{BG}$ aqueous dispersion. A similar behavior as the $\zeta$ potential versus BG dispersion was observed by Ishikawa et al. (2005) for gum arabic dispersions.

\section{Particle size distribution}

The analysis of particle size distribution based on light scattering intensity (Fig. 2) showed that the aqueous distribution of BG had a bimodal polydispersity behavior (Malvern, 2004). The distribution shows a smaller particle population with mean size of $45 \mathrm{~nm}$, represented by the less intense peak, and a peak with more intensity and scattering, which comprises particles with mean size of $648.1 \mathrm{~nm}$. The polydispersity index (PDI) observed for the aqueous dispersion of $\mathrm{BG}$ was equal to 1 (Bonatto and Silva, 2014). PDI values in the range of 0.05 to 0.08 correspond to monodisperse (monomodal) dispersions, whereas values between 0.08 and 0.70 characterize dispersions with intermediate polydispersity. In turn,

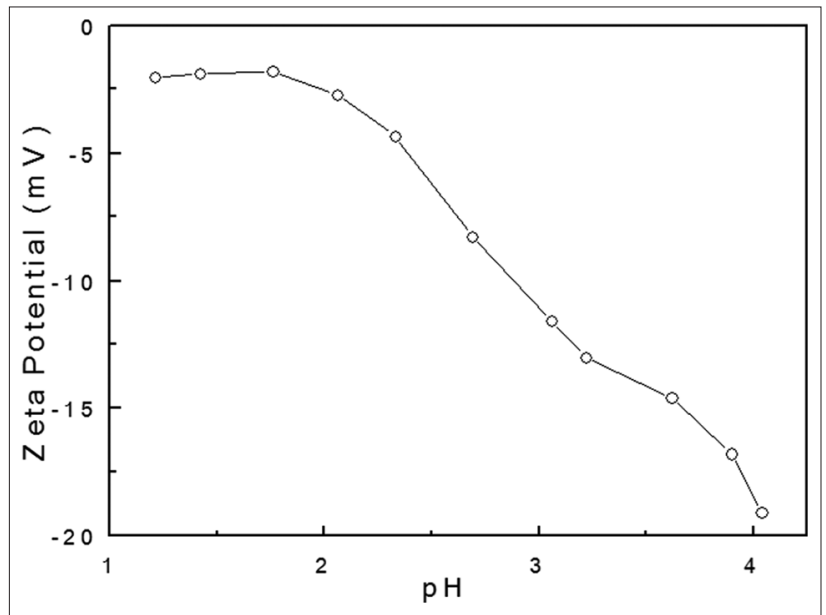

Fig 1. $\zeta$ potential of buriti tree gum in aqueous dispersion as a function of $\mathrm{pH}$.

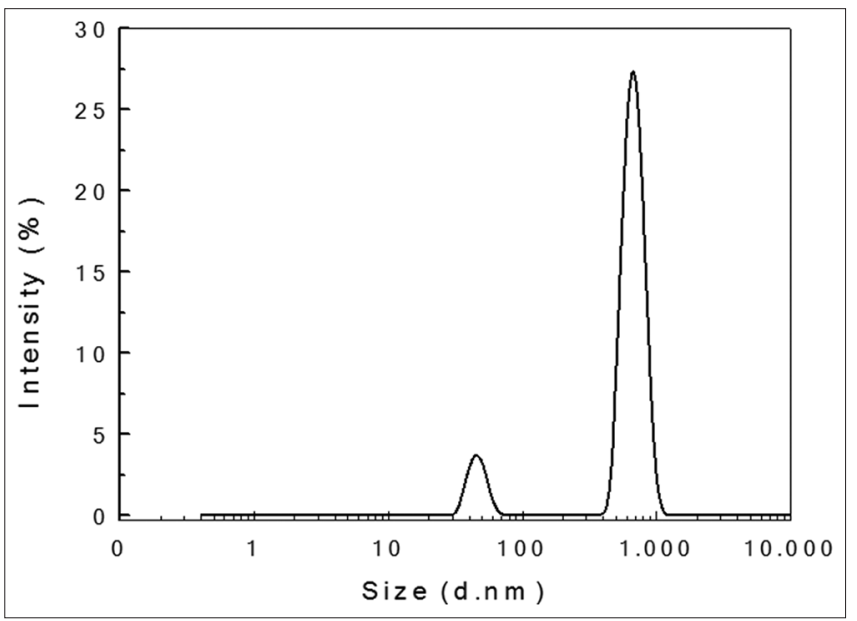

Fig 2. Frequency of particle size distribution of buriti tree gum. values of PDI $>0.70$ are attributed to more open polydispersivities, i.e., with greater variability in particle size (Felix et al., 2017).

\section{Rheological behavior of BG}

The flow curves of $B G$ in aqueous dispersion at the different concentrations (4 to $10 \%$ ) and temperatures $\left(10\right.$ to $\left.40^{\circ} \mathrm{C}\right)$ are presented in Fig. 3. A linear behavior can be seen between shear stress and shear rate for dispersions with 4 and $5 \%$ BG, which indicates a Newtonian behavior for those samples. In turn, dispersions with 8 and $10 \%$ BG had non-Newtonian fluid behavior with pseudoplastic characteristics (Naji-Tabasi and Razavi, 2015).

Overall, all models tested had good fits to the rheological data of BG dispersion in the experimental domain since all fits had high coefficient of determination $\left(r^{2}\right)$ values and low reduced chi-squared $\left(\chi^{2}\right)$ values (Table 1$)$. However, the Herschel-Bulkley model had the best statistical indices for all conditions studied (Fig. 3). This model, besides comprising the parameters consistency index $\left(k_{b l}\right)$ and flow behavior index $\left(n_{b b}\right)$, contemplates the yield stress $\left(\tau_{0}\right)$, which is the minimum tension required for flow to occur and below which the material exhibits characteristics of a solid (Steffe, 1996). The negative values indicate that the $\tau_{0}$ values observed have no physical meaning (Zimeri and Kokini, 2003) and, since the values are very close to zero, it can be said that there is no limiting shear stress. According to Zhu et al. (2001), the values observed for $\tau_{0}$ may be attributed to imprecision in data acquisition in low-velocity regions.

The good fits of the Newton model and the $n_{h b}$ values close to 1 for the dispersions with 4 and 5\% BG (Table 1) confirm the Newtonian character for all dispersions in these conditions. The $n_{b b}$ values away from 1 and the increase in the value of $k_{b b}$ confirm the change in fluid behavior for the dispersions with 8 and $10 \% \mathrm{BG}$, which started showing a pseudoplastic $\left(n_{b b}<1\right)$ character (Rao, 2013).

Oliveira et al. (2001) observed Newtonian behavior for aqueous dispersions of gum from Enterolobium contortisilliquum at concentrations of up to $1 \%$ and pseudoplastic behavior for higher concentrations. In turn, Mothe and Rao (1999) and Goycoolea et al. (1995) studied the rheological behavior of aqueous dispersions of cashew three (Anacardium occidentale) gum, mesquite (Prosopis spp.) gum, and gum arabic and observed that the aqueous dispersions of all gums behaved as Newtonian fluids at concentrations up to $20 \%$, after which they showed pseudoplastic behavior. That behavior is characteristic of gums that have good solubility and whose dispersions had low viscosities at up to higher concentrations (Andrews, 1993). 
Table 1: Parameters of the Newton, Power Law and Herschel-Bulkley models fitted to experimental data of aqueous dispersions of buriti tree gum

\begin{tabular}{|c|c|c|c|c|c|c|c|c|c|c|c|c|c|}
\hline \multirow[t]{2}{*}{$\mathrm{C} \%(\mathrm{~m} / \mathrm{v})$} & \multirow[t]{2}{*}{$\mathrm{T}\left({ }^{\circ} \mathrm{C}\right)$} & \multicolumn{3}{|c|}{ Newton $(\tau=\mu \gamma)$} & \multicolumn{4}{|c|}{ Power Law $\left(\tau=\mathrm{K} \gamma^{n}\right)$} & \multicolumn{5}{|c|}{ Herschel-Bulkley $\left(\tau=\tau_{0}+k_{h b} \gamma^{n_{h b}}\right)$} \\
\hline & & $\mu$ & $\chi^{2}$ & $r^{2}$ & $K$ & $n$ & $\chi^{2}$ & $r^{2}$ & $\tau_{0}$ & $\boldsymbol{k}_{h b}$ & $n_{h b}$ & $\chi^{2}$ & $r^{2}$ \\
\hline \multirow[t]{5}{*}{4} & 15 & 0.0174 & 0.1314 & 0.9886 & 0.0104 & 1.0846 & 0.1039 & 0.9910 & -0.6115 & 0.0234 & 0.9646 & 0.0708 & 0.9939 \\
\hline & 20 & 0.0159 & 0.1738 & 0.9828 & 0.0075 & 1.1239 & 0.1227 & 0.9878 & -0.6302 & 0.0189 & 0.9871 & 0.0858 & 0.9915 \\
\hline & 25 & 0.0139 & 0.2325 & 0.9715 & 0.0043 & 1.1933 & 0.1380 & 0.9831 & -0.6001 & 0.0122 & 1.0377 & 0.1019 & 0.9875 \\
\hline & 30 & 0.0129 & 0.1895 & 0.9732 & 0.0038 & 1.2030 & 0.0997 & 0.9859 & -0.5056 & 0.0099 & 1.0582 & 0.0740 & 0.9895 \\
\hline & 40 & 0.0102 & 0.2382 & 0.9510 & 0.0014 & 1.3286 & 0.0972 & 0.9800 & -0.3597 & 0.0036 & 1.1857 & 0.0832 & 0.9829 \\
\hline \multirow[t]{5}{*}{5} & 15 & 0.0247 & 0.1150 & 0.9945 & 0.0278 & 0.9801 & 0.1154 & 0.9944 & -0.7061 & 0.0517 & 0.8892 & 0.0770 & 0.9963 \\
\hline & 20 & 0.0215 & 0.1717 & 0.9898 & 0.0177 & 1.0316 & 0.1707 & 0.9899 & -0.7923 & 0.0398 & 0.9129 & 0.1191 & 0.9929 \\
\hline & 25 & 0.0198 & 0.1383 & 0.9902 & 0.0167 & 1.0280 & 0.1385 & 0.9902 & -0.6499 & 0.0347 & 0.9205 & 0.1051 & 0.9926 \\
\hline & 30 & 0.0179 & 0.1149 & 0.9904 & 0.0118 & 1.0689 & 0.0963 & 0.9920 & -0.5375 & 0.0237 & 0.9659 & 0.0719 & 0.9940 \\
\hline & 40 & 0.0154 & 0.1492 & & 0.0072 & 1.1243 & 0.1004 & 0.9894 & -0.6020 & 0.0181 & 0.9891 & 0.0662 & 0.9930 \\
\hline \multirow[t]{5}{*}{8} & 15 & 0.0473 & 0.8097 & 0.9875 & 0.1128 & 0.8568 & 0.0987 & 0.9985 & -0.2789 & 0.1276 & 0.8388 & 0.0968 & 0.9985 \\
\hline & 20 & 0.0448 & 0.5628 & 0.9907 & 0.0952 & 0.8761 & 0.0835 & 0.9986 & -0.6432 & 0.1279 & 0.8331 & 0.0561 & 0.9991 \\
\hline & 25 & 0.0422 & 0.3359 & 0.9938 & 0.0775 & 0.8998 & 0.0646 & 0.9988 & -0.5772 & 0.1036 & 0.8574 & 0.0416 & 0.9992 \\
\hline & 30 & 0.0367 & 0.1895 & 0.9957 & 0.0535 & 0.9381 & 0.1156 & 0.9974 & -0.7662 & 0.0836 & 0.8726 & 0.0725 & 0.9983 \\
\hline & 40 & 0.0333 & 0.1627 & 0.9954 & 0.0498 & 0.9337 & 0.0922 & 0.9974 & -0.6574 & 0.0761 & 0.8716 & 0.0612 & 0.9983 \\
\hline \multirow[t]{5}{*}{10} & 15 & 0.0725 & 2.9482 & 0.9796 & 0.2236 & 0.8145 & 0.0274 & 0.9998 & -0.3832 & 0.2483 & 0.7992 & 0.0185 & 0.9999 \\
\hline & 20 & 0.0683 & 2.1961 & 0.9832 & 0.1924 & 0.8295 & 0.0285 & 0.9998 & -0.3892 & 0.2158 & 0.8128 & 0.0190 & 0.9999 \\
\hline & 25 & 0.0625 & 1.5131 & 0.9865 & 0.1598 & 0.8454 & 0.0350 & 0.9997 & -0.4518 & 0.1853 & 0.8239 & 0.0217 & 0.9998 \\
\hline & 30 & 0.0617 & 1.4937 & 0.9862 & 0.1598 & 0.8434 & 0.0176 & 0.9998 & -0.2522 & 0.1739 & 0.8311 & 0.0137 & 0.9999 \\
\hline & 40 & 0.0527 & 1.3906 & 0.9823 & 0.1487 & 0.8291 & 0.0874 & 0.9989 & -0.5774 & 0.1848 & 0.7977 & 0.0676 & 0.9991 \\
\hline
\end{tabular}

The values are mean of a triplicate with variation coefficient $<5 \% ; \tau$ : Shear stress $(\mathrm{Pa}) ; \mu$ : Viscosity $(\mathrm{Pa} . \mathrm{s}) ; \gamma$ : Shear rate $\left(\mathrm{s}^{-1}\right) ; \tau_{0}:$ Yield stress $(\mathrm{Pa}) ; n, n_{h b}$ : Flow behavior indices (dimensionless); $k, k_{h b}$ : Consistency indices $\left(P a . s^{n}\right) ; r^{2}:$ Coefficient of determination; $\chi^{2}$ : Reduced Chi-squared
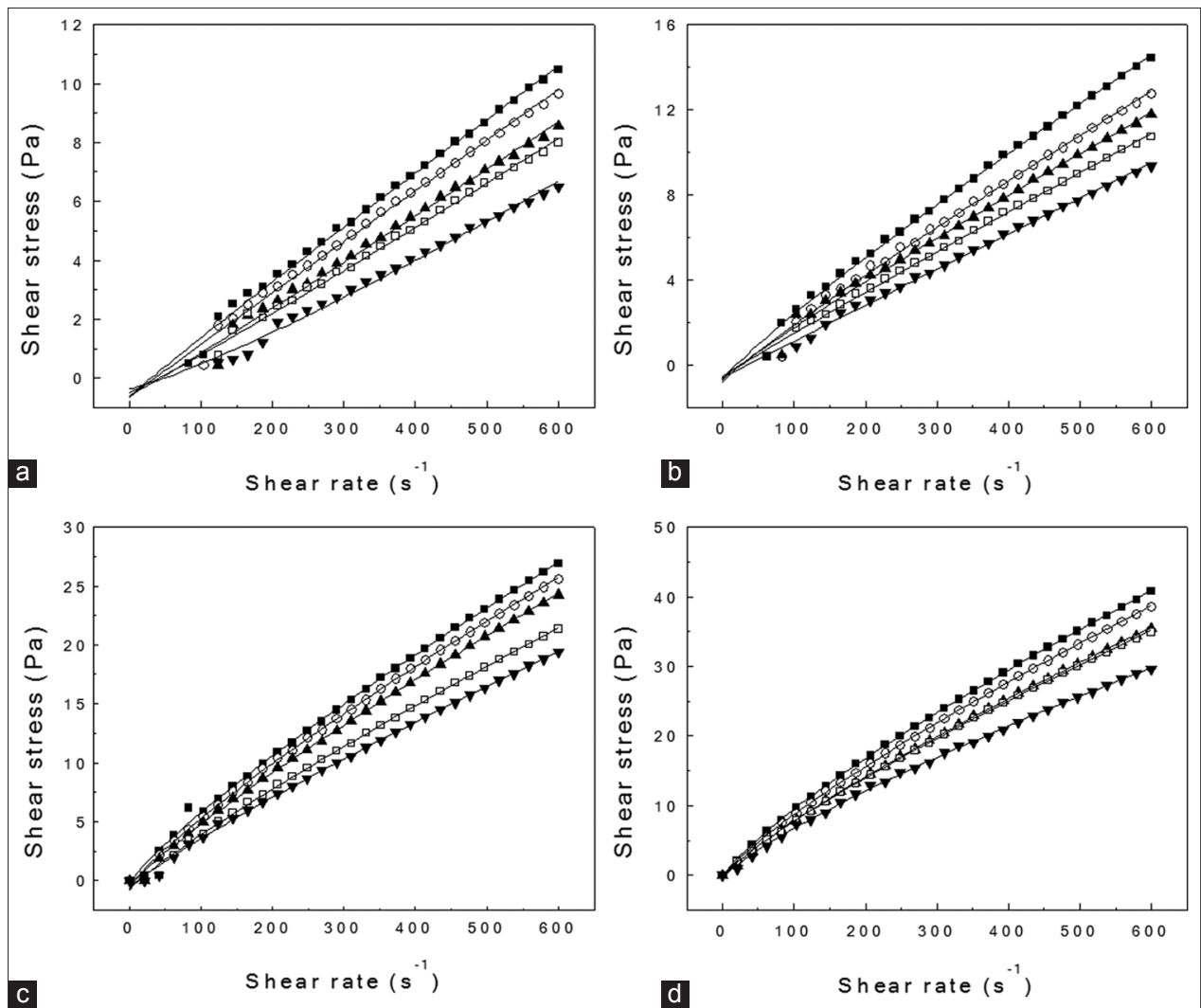

Fig 3. Flow and Herschel-Bulkley fitting curves for rheological behavior of 4 (a), 5 (b), 8 (c) and 10\% (m/v) (d) aqueous dispersions of buriti tree

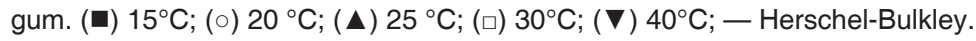


The rheological behavior observed for aqueous dispersions of $B G$ indicates that flow and pumping operations, for example, are facilitated when low concentrations, of up to $5 \% \mathrm{BG}$, are used. Under those conditions, the dispersion behaves as a Newtonian fluid and will have constant viscosity regardless of the effort applied (NajiTabasi and Razavi, 2015). Thus, dispersions with low BG concentrations may be used as additives in emulsions and ready-to-eat sauces (Bai et al., 2017). On the other hand, BG dispersions with concentrations above 5\% will require greater initial shear force until greater shear rates are reached, when the viscosity of the dispersion will drop along with shearing. That pseudoplastic nature may hamper the pumping process; however, it may be an adequate characteristic for application in controlled-release drug devices, for example (Sharma and Mazumdar, 2013).

Overall, the scientific literature indicates that the rheological behavior of gums obtained from plant exudates is mainly influenced by the structure, conformation, and inter- and intramolecular interactions of polymeric chains (Andrews, 1993). According to Naji-Tabasi and Razavi (2015), the drop in viscosity of gums as the shear rate increases, a typically pseudoplastic behavior, is attributed to the orientation of polymers, initially intertwined and entangled. $\mathrm{Li}$ and Nie (2016), in turn, concluded that the rheological responses of gum arabic to shearing are attributed to the presence of an equilibrium system (aggregation and disaggregation) of molecular chains instead of the linear orientation of molecules.

Based on information of the scientific literature, it is reasonable to assume that BG has a complex microstructure system with high degree of ramifications. That makes the dispersions with low gum concentrations have lower molecular coupling of polymeric chains whereas, at higher concentrations, the molecular interaction-aggregation of chains is favored (Li and Nie, 2016). That behavior justifies the transition from the Newtonian to the pseudoplastic regime observed for BG dispersions.

\section{Influence of temperature and concentration on BG rheology}

The viscosity of BG dispersions, at all concentrations studied, decreased as temperature increased (Fig. 4). The thermal stability of natural polymers is attributed to intramolecular attraction forces such as hydrogen bonds and Van der Waals force, while methyl and hydroxyl groups, as well as hemiacetal atoms, contribute to chain stability (Tako, 2015). The increase in temperature weakens the intra- and intermolecular attraction forces and results in the disorientation of polymeric chains, which leads to lower dispersion viscosity (Eren et al., 2015; Nwokocha and Williams, 2016). Particularly for polysaccharides, that effect also depends on the solution concentration, i.e., the higher the dispersion concentration, the lower the dependence on temperature with the molecular mobility of the polymer (Li and Nie, 2016), which can be seen in the slopes of the lines in Fig. 4.

Table 2 shows the activation energy $(E)$ values calculated for the BG dispersions at the different concentrations. $E_{a}$ represents the energy barrier to be overcome for flow to occur (Gong et al., 2012; Rao, 2013) and the higher its value, the greater the influence of temperature on product viscosity (Silva et al., 2005). The reduction in $E_{a}$ value as the $\mathrm{BG}$ dispersion concentration increases can be explained by the fact that the higher the concentration, the greater the inter- and intramolecular interactions of the polymer, thus inhibiting hydration with the consequent reduction of polymer breakdown, which contributes for viscosity to be less sensitive to temperature (Gong et al., 2012; Nwokocha and Williams, 2016).

Overall, the $E$ values obtained for BG dispersions match those observed for aqueous dispersions of other gums such as from Acacia tortuosa at $40 \% \mathrm{~m} / \mathrm{v}(19.5 \mathrm{~kJ} / \mathrm{mol}$ ) (Muñoz et al., 2007), Albiria lebbeck at $3 \% \mathrm{~m} / \mathrm{v}(17.2 \mathrm{~kJ} / \mathrm{mol})$, Acacia senegal at $2 \% \mathrm{~m} / \mathrm{v}(15 \mathrm{~kJ} / \mathrm{mol})$, Annacardium occidentale at $2 \% \mathrm{~m} / \mathrm{v}(16.2 \mathrm{~kJ} / \mathrm{mol})$, and Acacia macrocarpa at $2 \% \mathrm{~m} / \mathrm{v}$ (16.8 kJ/mol) (Paula et al., 2001).

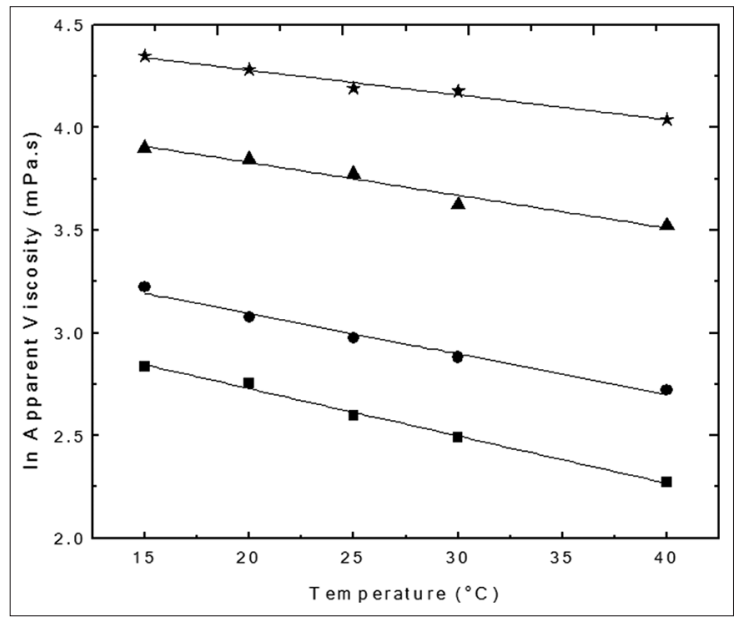

Fig 4. Influence of temperature on apparent viscosity of buriti tree gum at $310 \mathrm{~s}^{-1}$. (ロ) $4 \%(\bullet) 5 \%(\mathbf{\Delta}) 8 \%(\star) 10 \%$.

Table 2: Parameters of the Arrhenius model fitted to experimental data of aqueous dispersions of tree gum

\begin{tabular}{lcccc}
\hline $\boldsymbol{C}(\%, \mathrm{~m} / \mathrm{v})$ & $\boldsymbol{A}_{0}$ (Pa.s) & $\boldsymbol{E}_{\mathrm{a}}(\mathrm{kJ} / \mathrm{mol})$ & $\boldsymbol{r}^{2}$ & $\chi^{2}$ \\
\hline 4 & $1.23 \times 10^{-5}$ & 17.35 & 0.986 & $3.89 \times 10^{-4}$ \\
5 & $4.95 \times 10^{-5}$ & 14.85 & 0.958 & $4.97 \times 10^{-4}$ \\
8 & $3.32 \times 10^{-4}$ & 12.01 & 0.958 & $1.02 \times 10^{-4}$ \\
10 & $1.74 \times 10^{-3}$ & 9.07 & 0.972 & $3.82 \times 10^{-4}$ \\
\hline
\end{tabular}

The values are mean of a triplicate with variation coefficient $<$ $5 \% ; A_{0}$ : Empirical constant; $E_{a}$ : Activation energy; $r^{2}$ : Coefficient of determination; $\boldsymbol{X}^{2}$ : Reduced Chi-squared 


\section{CONCLUSION}

The characterization of polysaccharides from new plant sources is an alternative to provide low-cost resources with good technological and industrial performance. In this context, the centesimal composition of the gum extracted from the exudate of buriti tree trunk (BG) was similar to the composition of gum from Acacia farnesiana, a gum arabic species. In addition, the aqueous dispersion of $B G$ had intermediate colloidal stability ( $\zeta$ potential $=-17.1 \mathrm{mV}$ ), polydispersity in relation to particle size distribution (PDI = 1), and a tendency for greater colloidal stability at $\mathrm{pH}>4$. The flow curves of aqueous BG dispersion were satisfactorily described by the Herschel-Bulkley model. The aqueous dispersion of $\mathrm{BG}$ had Newtonian fluid behavior at low concentration ( 4 and $5 \% \mathrm{~m} / \mathrm{v}$ ) and started behaving as a pseudoplastic fluid at higher concentrations (8 and $10 \% \mathrm{~m} / \mathrm{v}$ ), which indicates versatility for the technological application of the gum. The activation energy values indicated a reduction in sensitivity of viscosity of aqueous dispersion of $\mathrm{BG}$ to the effects of temperature as the $\mathrm{BG}$ concentration in the dispersion increased.

\section{ACKNOWLEDGEMENTS}

The authors would like to thank Dr. Antonio Manoel da Cruz Rodrigues (FEA/ITEC/UFPA) for the contribution in the rheological experiments.

\section{Authors' contributions}

D. A. Silva performed all analysis, collected all test data, interpreted the results and drafted the manuscript. P. H. Santos interpreted the results and drafted the manuscript. R. S. Pena designed the study and interpreted the results.

\section{REFERENCES}

Abdolmaleki, K., M. A. Mohammadifar, R. Mohammadi, G. Fadavi and N. M. Meybodi. 2016. The effect of $\mathrm{pH}$ and salt on the stability and physicochemical properties of oil-in-water emulsions prepared with gum tragacanth. Carbohydr. Polym. 140: 342-348.

Al-Assaf, S., M. Sakata, C. McKenna, H. Aoki and G. O. Phillips. 2009. Molecular associations in acacia gums. Struct. Chem. 20: 325.

Alghooneh, A., S. M. A. Razavi and F. Behrouzian. 2017. Rheological characterization of hydrocolloids interaction: A case study on sage seed gum-xanthan blends. Food Hydrocoll. 66: 206-215.

Andrews, B. 1993. Industrial gums. Polysaccharides and their derivatives. Food Chem. 48: 329.

AOAC. 1995. Official Methods of Analysis. $16^{\text {th }}$ ed. Association of Official Analytical Chemists, Arlington, VA.

Bai, L., S. Huan, Z. Li and D. J. McClements. 2017. Comparison of emulsifying properties of food-grade polysaccharides in oil-inwater emulsions: Gum arabic, beet pectin, and corn fiber gum. Food Hydrocoll. 66: 144-153.
Bashir, M. and S. Haripriya. 2016. Assessment of physical and structural characteristics of almond gum. Int. J. Biol. Macromol. 93: 476-482.

Bohmer, M. R., O. A. Evers and J.M. Scheutjens. 1990. Weak polyelectrolytes between two surfaces: Adsorption and stabilization. Macromolecules. 23: 2288-2301.

Bonatto, C. C. and L. P. Silva. 2014. Higher temperatures speed up the growth and control the size and optoelectrical properties of silver nanoparticles greenly synthesized by cashew nutshells. Ind. Crops Prod. 58: 46-54.

Carneiro-Da-Cunha, M. G., M. A. Cerqueira, B. W. Souza, J. A. Teixeira and A. A. Vicente. 2011. Influence of concentration, ionic strength and $\mathrm{pH}$ on zeta potential and mean hydrodynamic diameter of edible polysaccharide solutions envisaged for multinanolayered films production. Carbohydr. Polym. 85: 522-528.

Cruz, R. C., A. M. Segadães, R. Oberacker and M. J. Hoffmann. 2017. Double layer electrical conductivity as a stability criterion for concentrated colloidal suspensions. Colloids Surf. A. 520: 9-16.

Eddy, N. O., I. Udofia, A. Uzairu, A. O. Odiongenyi and C. Obadimu. 2014. Physicochemical, spectroscopic and rheological studies on eucalyptus citriodora (EC) gum. J. Polym. Biopolym. Phys. Chem. 2: 12-24.

Eren, N. M., P. H. Santos and O. Campanella. 2015. Mechanically modified xanthan gum: Rheology and polydispersity aspects. Carbohydr. Polym. 134: 475-484.

Fadavi, G., M. A. Mohammadifar, A. Zargarran, A. M. Mortazavian and R. Komeili. 2014. Composition and physicochemical properties of Zedo gum exudates from Amygdalus scoparia. Carbohydr. Polym. 101: 1074-1080.

Felix, M., A. Romero and A. Guerrero. 2017. Viscoelastic properties, microstructure and stability of high-oleic O/W emulsions stabilised by crayfish protein concentrate and xanthan gum. Food Hydrocoll. 64: 9-17.

Gong, H., M. Liu, J. Chen, F. Han, C. Gao and B. Zhang. 2012. Synthesis and characterization of carboxymethyl guar gum and rheological properties of its solutions. Carbohydr. Polym. 88: 1015-1022.

Goycoolea, F., E. Morris, R. Richardson and A. Bell. 1995. Solution rheology of mesquite gum in comparison with gum arabic. Carbohydr. Polym. 27: 37-45.

Imam, S. H., C. Bilbao-Sainz, B. S. Chiou, G. M. Glenn and W. J. Orts. 2013. Biobased adhesives, gums, emulsions, and binders: Current trends and future prospects. J. Adhes. Sci. Technol. 27: 1972-1997.

Ishikawa, Y., Y. Katoh and H. Ohshima. 2005. Colloidal stability of aqueous polymeric dispersions: Effect of $\mathrm{pH}$ and salt concentration. Colloids Surf. B. 42: 53-58.

Li, J. M. and S. P. Nie. 2016. The functional and nutritional aspects of hydrocolloids in foods. Food Hydrocoll. 53: 46-61.

Malvern, I. 2004. Zetasizer Nano Series User Manual. Malvern Instruments Ltd., Worcestershire.

Maranzano, B. J. and N. J. Wagner. 2001. The effects of interparticle interactions and particle size on reversible shear thickening: Hard-sphere colloidal dispersions. J. Rheol. 45: 1205-1222.

Mirhosseini, H., C. P. Tan, N. S. Hamid and S. Yusof. 2008 Optimization of the contents of Arabic gum, xanthan gum and orange oil affecting turbidity, average particle size, polydispersity index and density in orange beverage emulsion. Food Hydrocoll. 22: $1212-1223$

Mothe, C. and M. Rao. 1999. Rheological behavior of aqueous dispersions of cashew gum and gum arabic: Effect of concentration and blending. Food Hydrocoll. 13: 501-506. 
Muñoz, J., F. Rincon, M. C. Alfaro, I. Zapata, J. Fuente, O. Beltrán and G. L. Pinto. 2007. Rheological properties and surface tension of Acacia tortuosa gum exudate aqueous dispersions. Carbohydr. Polym. 70: 198-205.

Naji-Tabasi, S. and S. M. A. Razavi. 2015. New studies on basil (Ocimum bacilicum L.) seed gum: Part III-steady and dynamic shear rheology. Food Hydrocoll. 67: 243-250.

Nussinovitch, A. 2010. Plant Gum Exudates of The World. CRC Press, Boca Raton.

Nwokocha, L. M. and P. A. Williams. 2016. Rheological properties of a polysaccharide isolated from Adansonia digitata leaves. Food Hydrocoll. 58: 29-34.

Oliveira, J., D. Silva, R. de Paula, J. Feitosa and H. Paula. 2001. Composition and effect of salt on rheological and gelation properties of Enterolobium contortisilliquum gum exudate. Int. J. Biol. Macromol. 29: 35-44.

Paraskevopoulou, A., D. Boskou and V. Kiosseoglou. 2005. Stabilization of olive oil-lemon juice emulsion with polysaccharides. Food Chem. 90: 627-634.

Paula, R., S. Santana and J. Rodrigues. 2001. Composition and rheological properties of Albizia lebbeck gum exudate. Carbohydr. Polym. 44: 133-139.

Phillips, G. O. 2000. Colloids: A Partnership with Nature A2-Nishinari, Katsuyoshi, Hydrocolloids. Elsevier Science, Amsterdam.

Rao, A. 2013. Rheology of Fluid, Semisolid, and Solid Foods: Principles and Applications. $3^{\text {rd }}$ ed. Springer, New York.

Rao, A. M. 1999. Rheology of Fluid and Semisolid Fluids: Principles and Applications. Aspen Publication, Gaithersburg, MD.

Sharma, V. K. and B. Mazumdar. 2013. Feasibility and characterization of gummy exudate of Cochlospermum religiosum as pharmaceutical excipient. Ind. Crops Prod. 50: 776-786.

Sibaja-Hernández, R., A. Román-Guerrero, G. Sepúlveda-Jiménez and M. Rodríguez-Monroy. 2015. Physicochemical, shear flow behaviour and emulsifying properties of Acacia cochliacantha and Acacia farnesiana gums. Ind. Crops Prod. 67: 161-168.

Silva, F. C., D. H. P. Guimarães and C. Gasparetto. 2005. Rheology of acerola juice: Effects of concentration and temperature. Ciênc. Tecnol. Aliment. 25: 121-126.

Smith, N. 2014. Palms and People in the Amazon. Springer, Gainesville.

Steffe, J. F. 1996. Rheological Methods in Food Process Engineering. $2^{\text {nd }}$ ed. Freeman Press, Michigan.

Tako, M. 2015. The principle of polysaccharide gels. Adv. Biosci. Biotechnol. 6: 22.

Tonon, R., D. Alexandre, M. Hubinger, R. Cunha. 2009. Steady and dynamic shear rheological properties of açai pulp (Euterpe oleraceae Mart.). J. Food Eng. 92: 425-431.

Vasile, F. E., M. J. Martinez, V. M. P. Ruiz-Henestrosa, M. A. Judis and M. F. Mazzobre. 2016. Physicochemical, interfacial and emulsifying properties of a non-conventional exudate gum (Prosopis alba) in comparison with gum arabic. Food Hydrocoll. 56: 245-253.

Yaseen, E., T. Herald, F. Aramouni and S. Alavi. 2005. Rheological properties of selected gum solutions. Food Res. Int. 38: 111-119.

Zhu, L., N. Sun, K. Papadopoulos and D. de Kee. 2001. A slotted plate device for measuring static yield stress. J. Rheol. 45: 1105-1122.

Zimeri, J. and J. Kokini. 2003. Rheological properties of inulin-waxy maize starch systems. Carbohydr. Polym. 52: 67-85. 